Review

\title{
Biologic Mechanisms Linked to Prognosis in Ovarian Cancer that May Be Affected by Aging
}

\author{
Hye Sook Chon ${ }^{1,5}$, Marina Sehovic ${ }^{2,3}$, Douglas Marchion, ${ }^{4}$ Christine Walko ${ }^{3}$, Yin Xiong4, Martine \\ Extermann $2,3,5 \bowtie$ \\ 1. Department of Gynecology Oncology, Moffitt Cancer Center and Research Institute, Tampa FL, USA \\ 2. Senior Adult Oncology Program, Moffitt Cancer Center and Research Institute, Tampa FL, USA \\ 3. Department of Individualized Cancer Management, Moffitt Cancer Center and Research Institute, Tampa FL, USA \\ 4. Department of Pathology, Moffitt Cancer Center and Research Institute, Tampa FL, USA \\ 5. University of South Florida, Tampa FL, USA \\ $\square$ Corresponding author: Martine Extermann, MD, PhD, Senior Adult Oncology, Moffitt Cancer Center, 10920 McKinley Drive, Tampa, FL 33612, USA. \\ Telephone: +1(813)745-3822; Fax: +1(813)745-1908; E-mail: martine.extermann@moffitt.org \\ (c) Ivyspring International Publisher. This is an open access article distributed under the terms of the Creative Commons Attribution (CC BY-NC) license \\ (https://creativecommons.org/licenses/by-nc/4.0/). See http://ivyspring.com/terms for full terms and conditions.
}

Received: 2018.08.30; Accepted: 2019.04.27; Published: 2019.06.02

\begin{abstract}
The increase of both life expectancy of the Western industrialized population and cancer incidence with aging is expected to result in a rapid expansion of the elderly cancer population, including patients with epithelial ovarian cancer (EOC). Although the survival of patients with EOC has generally improved over the past three decades, this progress has yet to provide benefits for elderly patients. Compared with young age, advanced age has been reported as an adverse prognostic factor influencing EOC. However, contradicting results have been obtained, and the mechanisms underlying this observation are poorly defined. Few papers have been published on the underlying biological mechanisms that might explain this prognosis trend. We provide an extensive review of mechanisms that have been linked to EOC prognosis and/or aging in the published literature and might underlie this relationship in humans.
\end{abstract}

Key words: ovarian cancer, aging, inflammation, immunoscenescence, prognosis, biology of aging and cancer

\section{Introduction}

Epithelial ovarian cancer (EOC) is the most lethal gynecologic cancer, with half of the cases occurring above the age of 65 years [1]. The survival of women with EOC strongly decreases with age and, whereas in younger women the 5-year survival has increased by $15 \%$ to $20 \%$ since 1975 , the rate has not changed in older women [2]. The reasons for this increased aggressiveness are still poorly understood. Without EOC, a 75-year-old woman has a life expectancy of 12 years and an 85-year-old woman has a life expectancy of 7 years. Therefore, competing mortality can only explain a small part of the increased mortality of older EOC patients. Other contributing factors include undertreatment and early treatment discontinuation $[3,4]$. Yet, even adjusting for patient characteristics, stage, and treatment delivered, the risk of dying from EOC in older women is 1.8 times higher that of women under 70 years $[5,6]$. Few papers have been published on the underlying biological mechanisms that might explain this prognosis trend. Therefore we undertook a broad review of mechanisms that have been linked to EOC prognosis and/or aging in patients with EOC in the published literature (Table $1)$.

\section{Methods}

We developed this expert review by focusing on the question: "What biological mechanisms may underlie the worse prognosis of ovarian cancer with aging?" We developed a 3-step approach: First, we created a table of all the mechanisms we could find via PubMed or cross references that had been linked either to prognosis in EOC or to aging. We placed as a restriction that the mechanisms considered should 
have at least one report on patient tissue or human studies. Once we identified a list of potential candidates we repeated the search to find corresponding data in the literature on either the aging (if the initial mechanism was linked to EOC) or EOC (if the initial mechanism was linked to aging), and integrated the findings in a first draft. The final selection was made to present in this review the mechanisms that have the strongest evidence linking both EOC prognosis and aging. Ideally, these would be found in a single article, but such articles are exceedingly rare. Therefore our report adopts the following general format: Association of the mechanism with EOC prognosis; association with aging; association with age in EOC. Each mechanism section has a short summary paragraph. An overview is provided in Table 1. We offer general thoughts at the end of the article.

Table 1. Biologic mechanisms linked to ovarian cancer prognosis in possible relationship to aging

\begin{tabular}{|c|c|}
\hline Biologic Mechanisms & Key findings \\
\hline $\begin{array}{l}\text { 1.Cellular and humoral } \\
\text { immunity }\end{array}$ & $\begin{array}{l}\text { Strong evidence that cellular and humoral } \\
\text { immunity is associated with outcomes in EOC. } \\
\text { Aging induces multiple changes in cellular } \\
\text { immunity and more broadly immune response. } \\
\text { Not studied together yet, but promising } \\
\text { potential. }\end{array}$ \\
\hline 2.Cytokines and inflammation & $\begin{array}{l}\text { The literature on inflammation and } \\
\text { inflammaging suggests potential links with } \\
\text { outcomes, best documented for IL- } 6 \text { and CRP, } \\
\text { although the role of confounding factors needs } \\
\text { to be clarified. }\end{array}$ \\
\hline $\begin{array}{l}\text { 3.Microenvironment, } \\
\text { angiogenesis }\end{array}$ & $\begin{array}{l}\text { VEGF and its modulation have demonstrated a } \\
\text { role in EOC. The microenvironment seems to } \\
\text { play a key role in this setting and is the focus of } \\
\text { intense research. Aging affects the } \\
\text { microenvironment, as senescent cells create a } \\
\text { SASP. While literature linking the two is still } \\
\text { lacking, this appears a very promising venue to } \\
\text { research, as well as large potential for } \\
\text { therapeutic interventions. }\end{array}$ \\
\hline $\begin{array}{l}\text { 4.Chemotherapy resistance } \\
\text { mechanisms }\end{array}$ & $\begin{array}{l}\text { The etiology of chemoresistance in EOC is } \\
\text { heterogeneous with few studies specifically } \\
\text { linking age related factors to occurrence. }\end{array}$ \\
\hline $\begin{array}{l}\text { 5.DNA damage/Telomeres, Cell } \\
\text { cycle } \\
\text { regulation/apoptosis/senescence }\end{array}$ & $\begin{array}{l}\text { Telomere length and p16 } 16^{\mathrm{INK} 4 \mathrm{~A}} \text { appear interesting } \\
\text { primary targets of exploration with some } \\
\text { evidence to support an association with } \\
\text { prognosis. }\end{array}$ \\
\hline 6.Metabolites & $\begin{array}{l}\text { As the prevalence of low Vitamin D levels } \\
\text { increases in an aging population and is } \\
\text { associated with worse cancer prognosis, it may } \\
\text { explain some of the link of age with worse } \\
\text { prognosis, although this has not been formally } \\
\text { demonstrated. The role of the } \\
\text { insulin/IGF-1pathway is more complex to } \\
\text { assess. }\end{array}$ \\
\hline 7.Epigenetics and miRNAs & $\begin{array}{l}\text { Methylation changes occur in both ovarian } \\
\text { cancer and aging. Some aging-similar } \\
\text { methylation patterns have been observed in a } \\
\text { study of patients with active ovarian cancer, but } \\
\text { more work needs to be done to understand its } \\
\text { significance. Some miRNA have been reported } \\
\text { to be associated with both ovarian cancer and } \\
\text { aging and are related to the control of immune } \\
\text { function and inflammation. }\end{array}$ \\
\hline $\begin{array}{l}\text { 8.Mitochondria related gene } \\
\text { alterations, oxidation } \\
\text { mechanisms }\end{array}$ & $\begin{array}{l}\text { While oxidative stress offers some hypothetical } \\
\text { links between aging and EOC prognosis, little } \\
\text { evidence is available so far to test this } \\
\text { hypothesis. }\end{array}$ \\
\hline
\end{tabular}

\section{Results}

\section{Cellular and humoral Immunity}

\section{1.a. Association with EOC prognosis}

EOC has an intimate interaction with host immune cells. The ability of primary EOC to metastasize first involves shedding of tumor cells from the primary ovarian mass to the peritoneal fluid or ascites [7]. These malignant cells within the ascites exist in suspension alongside a complex milieu of stromal cells, immune cells, and soluble factors. It has long been recognized that the presence of tumor infiltrating lymphocytes, notably $\mathrm{CD} 3+\mathrm{T}$ cells, associated with the primary ovarian mass equated to longer overall survival [8, 9]. However an immune-suppressive subset of $\mathrm{T}$ cells, $\mathrm{T}$ regulatory cells (Tregs) defined as CD4+, CD25+, FoxP3+ [10, 11] were reported to increase in numbers in EOC patients [12], and the accumulation of Tregs in ovarian tumors correlates with poor outcome [13-17]. In contrast, the presence of $\mathrm{CD} 8+$, or cytotoxic $\mathrm{T}$ cell infiltrates in ovarian tumors has been associated with better outcome and may be more predictive than other $\mathrm{T}$ cell subsets $[8,15,18]$. T cell ratios may also correlate with outcome as several reports have observed a higher ratio of CD8+ T cells to CD4+, CD25+, FoxP3+ Tregs correlated with improved overall survival $[13,19]$. A comprehensive assessment of immune cells as prognostic factors in EOC was recently performed by Santoiemma et al [20]. In an immunohistochemistry analysis of an ovarian cancer tissue microarray comprised of 135 cases, these researchers reported that infiltrating $\mathrm{CD} 3+\mathrm{T}$ cells were positively associated with response to chemotherapy while CD4+ cells were negatively associated with response to chemotherapy. Further, the presence of infiltrating CD8+ $\mathrm{T}$ cells and the ratio of CD8+ to FoxP3+ T cells were prognostic of improved 5 and/or 10 year survival [20].

Further, tumor cell surface receptors that modulate the immune response have increasingly become the targets of novel therapeutics and are the subject of many ongoing clinical trials [21, 22]. Checkpoint inhibitors against programmed death 1 (PD1), cytotoxic T lymphocyte antigen 4 (CTLA-4) and programmed death ligand 1 (PDL1) continue to be actively investigated [22-24]. The expression of programmed death ligand 1 (PDL1) on primary EOC tumors was shown to be an overall negative predictor of survival [25, 26]. Additionally, it was reported that expression of PDL1 can be induced on cells in ascites of an EOC mouse model and correlates with peritoneal spread [27]. Modulation of the major histocompatibility complex (MHC) I expression is a 
known mechanism of tumor immune evasion [28, 29]. Mariya et al, reported that low MHC I expression correlated with poor prognosis in serous EOC as well as endometrioid and mucinous EOC $[28,30]$.

The role of CD20+ B cells in EOC is not clearly understood [31, 32], although some literature suggests that increased B cell infiltrates was associated with longer survival times [20, 31, 33]. Natural killer cells have a known role in anti-tumor response and are associated with improved prognosis in EOC [34]. In contrast, CD68+ macrophage acquire an immunosuppressive phenotype (M2 phenotype) when in proximity to tumor tissue and contribute to disease progression. However, CD68+ macrophage were reported to have no benefit or provide a disadvantage to survival [35, 39].

Strategies to target EOC with tumor-specific antibodies have been more elusive, likely secondary to lack of an optimal surface antigen. A 2014 Cochrane review of trials using antigen-specific targeting failed to establish a conclusive evidence for efficacy of such strategies in EOC [35]. The majority of studies were targeted for CA-125 targeted antibody therapy. There was increased survival in humoral and/or cellular responders in non-randomized clinical trials but large randomized placebo-controlled trials did not show any clinical benefit despite induction of immune responses in approximately $60 \%$ of participants [36, 37].

Several different vaccination approaches have been explored in EOC including simple vaccine preparations consisting of specific peptides and proteins, as well as more complex strategies, such as engineered cellular vaccines, dendritic cell (DC) vaccines, virus-vectored vaccines, and oncolytic viruses. The majority of the vaccines have focused on using cancer-testis antigens (e.g. NY-ESO-1), and proteins known to be overexpressed in EOC (e.g. p53, survivin, MUC1). In general, while the majority of the studies demonstrated evidence of cellular and humoral response to the antigens, clinical benefit afforded by vaccination has unfortunately been marginal at best [35]. Since most of the strategies have relied on self-antigens, it is likely that vaccination alone is not sufficient to overcome the $\mathrm{T}$ cell tolerance and combinatorial therapies may be necessary.

\section{1.b. Association with aging}

Aging has long been known to be associated with immune system changes. It is also known that immune profiles are associated with survival. An "immune risk profile" comprising an inverted CD4:CD8 ratio, accumulation of CD8+ CD28late-differentiated $\mathrm{T}$ cells, poor proliferative capacity, few B cells and CMV-seropositivity, is associated with significantly increased 2-, 4- and 6-year mortality in very elderly people. Expression of CD95 on lymphocytes can be predictive of successful aging. In the section above, we identified some key factors in the association of cellular immunity with prognosis of EOC. The presence of infiltrating CD8+ cells and a better CD8/Tregs ratio is associated with a better prognosis in several studies. Cellular immunity is one of the key areas impacted by immunosenescence. Aging is associated with a decrease in NK cell function, a decrease in NK cell activation receptors, and an increase in inhibitory Killer-cell Immunoglobulin-like Receptor (KIR) expression. It is also associated with an increase in exhausted CD8+ T-cells that are unable to undergo clonal expansion and interfere with immune response to tumors. That increase in senescent CD8+ T-cells has been associated with an increased incidence of both solid and hematologic malignancies. A good string of data point to an association of this CD 8+ T-cells exhaustion with persisting antigenic stimulation linked to $\mathrm{CMV}$ infection [38]. Exercise might help reduce senescent CD8+ T cells (at least in the short term) [39]. Dendritic cells decrease in numbers and in positive costimulatory proteins, but show an increase in PD-L1 expression, resulting in decreased T-cell activation [38].

\section{1.c Association with age in EOC}

We did not find articles exploring and/or linking age-associated changes in immunity with prognosis in EOC.

\section{1.d Summary}

In summary, there is strong evidence that cellular and humoral immunity is associated with outcomes in EOC. Aging induces multiple changes in cellular immunity and more broadly immune response. The two phenomena have not been studied together yet, but the data hint on a promising venue to explore for understanding the worsening of EOC prognosis with age.

\section{Cytokines and inflammation}

\section{2.a. Association with prognosis in EOC}

A large amount of data supports the involvement of the inflammatory stromal microenvironment, caused by overexpression of cytokines or chemokines, in promoting EOC tumorigenesis, progression and resistance to chemotherapy. The tumor milieu in EOC development is enriched with a broad spectrum of pro-inflammatory cytokines and chemokines. In particular, several of these cytokines, such as tumor necrosis factor (TNF)- $a$, interleukin (IL)-1, IL-6, and 
IL-8 produced by tumor itself and/or activated by immune cells are known to influence clinical disease status and prognosis [40-43].

IL-6 is a pleiotropic cytokine that has both antiand pro-inflammatory roles. It is a potent pro-angiogenic cytokine secreted by EOC cells, mesothelial cells, fibroblast or macrophages [44]. IL-8 is a pro-inflammatory chemokine secreted by multiple cell types such as monocytes, mesothelial cells, endothelial cells, and tumor cells. C-reactive protein (CRP) is one of the most important acute phase proteins produced in response to inflammation and has both pro-inflammatory and anti-inflammatory actions.

Higher serum and ascites levels of these cytokines have been found in patients with EOC than in patients with other malignancies, and levels have been also shown to correlate with the extent of disease and poor clinical outcome $[41,45]$. In addition to its local effects in the tumor microenvironment, tumor -derived IL-6 can stimulate paraneoplastic thrombocytosis in patients with advanced EOC that, in turn, is associated with poor prognosis [45]. Cytokines and chemokines have also been evaluated as biomarkers for progression-free survival (PFS) and overall survival (OS) in advanced EOC. Kolomeyevskaya et al showed that ascites levels of tumor necrosis factor (TNF)- $\alpha$, IL-6 in pretreatment condition were associated shorter PFS intervals [46].

Biologic effects of other cytokines have been studied in the cytokine network of malignant ascites fluid. Matte et al reported higher levels of osteprotegerin (OPG), IL-10 and leptin in EOC ascites were associated with shorter PFS. IL-10 was shown to promote the anti-apoptotic activity of malignant ascites whereas OPG did not [47].

\section{2.b Association with aging (in general)}

Among the aging-associated immune system changes, impaired innate immunity as measured by low production capacity of pro- and anti-inflammatory cytokines is predictive of frailty in elderly and associated with a two-fold overall mortality risk [48]. Studies in centenarians indicate that these individuals present both an increase in inflammatory molecules (IL-6, IL-15, IL-18, CRP, serum amyloid A, fibrinogen, von Willebrand factor, resistin and leukotrienes), and a concomitant large quantity of anti-inflammatory molecules (adiponectin, TGF- $\beta$, IL-1 receptor antagonist, cortisol, anti-inflammatory arachidonic compounds). This suggests that an optimal balance might be linked to successful longevity [49]. Inflammaging is also associated with changes in the hematopoietic balance favoring the myeloid over the lymphoid lineage [50].
Interleukin-6 (IL-6) levels increase with age and it plays central roles in initiating and modulating inflammatory responses to injury and infection [51]. It is thought to reflect an age-associated loss of regulation of the IL-6 gene. IL-6 rise is also associated with obesity, comorbidity burden, leukocytosis, and slower walking speed, a robust predictor of mortality $[52,53]$. The rise of IL-6 and CRP are both good predictors of mortality, as well as physical and cognitive performance, in elderly cohorts of both successful aging and usual aging individuals [54, 55].

The identification of key inflammatory markers associated with prognosis in cancer and aging is an ongoing one. An emerging index is the Glasgow prognostic score (GPS), associating CRP and albumin levels. It appears not only to be associated with aging, but also with multi-morbidity, and supports a role of inflammation as a mediator of the negative impact of multi-morbidity on the behavior of cancer itself [56]. Other large inflammation and aging studies have identified similar predictors. For example, IL-6 and D-dimers correlated with higher mortality at 5 years and decrease function at 4 years [57]. In the In Chianti study, an inflammatory index: $\log ($ IL-6) $+2 \log$ (sTNFR1) correlate with 10 year mortality in elderly [58].

\section{2.c Association with age in EOC}

In a multicenter study, both age and CRP were associated with worse prognosis in EOC patients, but the effect of age completely disappeared in multivariable analysis while the effect of CRP was maintained, suggesting the hypothesis that CRP or covarying inflammation mechanisms might mediate part of the worse prognosis with aging. Patients with serum CRP $<$ or $=1 \mathrm{mg} / \mathrm{dL}$ versus $>1 \mathrm{mg} / \mathrm{dL}$ had an overall 5-year survival of $82 \%$ versus $58.5 \%(\mathrm{P}<0.001)$ [59].

\section{2.d Summary}

In summary, the literature on inflammation and inflammaging suggest potential links with outcomes, best documented for IL- 6 and CRP, although the role of confounding factors needs to be clarified.

\section{Microenvironment, angiogenesis}

\section{3.a. Association with prognosis in EOC}

Tumors are complex tissues composed of tumor cells, as well as stroma consisting of blood and lymphoid vessels, nerves, fibroblasts and extracellular matrix proteins, endothelial cells, pericytes, and immune cells. These collectively comprise the tumor microenvironment. It is becoming apparent that the microenvironment plays an important role in allowing the tumor to express its full neoplastic 
phenotype and that non-malignant cells have potential as therapeutic targets. For example, growing evidence suggest that cancer promotes increased micro-vessel density, recruits reactive stromal fibroblasts and different inflammatory cells and releases peptide-signaling molecules and proteases [44].

Among multiple microenvironment components, significant progress has been made for vascular endothelial growth factor (VEGF) in EOC last decade [60]. Its expression correlates with initial stage at diagnosis and shorter PFS and OS in EOC [61]. Bevacizumab, a monoclonal antibody to VEGF-A, was first demonstrated to have an antitumor activity as monotherapy in recurrent EOC in 2007 and has since become an important and potent therapeutic agent in the management of EOC [62].

Furthermore, the role of VEGF in tumor immunity has been recently reported by Horikawa et al. [63]. They analyzed 56 advanced high-grade serous ovarian cancer (HGSOC) cases by gene expression microarray and immunohistochemistry for VEGF, $\mathrm{CD} 8$, and CD33 to reveal that the upregulation of several myeloid cell chemoattractants and the downregulation of lymphocytes-related pathways in cases with high VEGF expression. VEGF expression correlated with myeloid-derived suppressor cells (MDSC) infiltration in immunohistochemical analysis. Cases with high MDSC infiltration, which was inversely correlated with intratumoral CD8+ T-cell infiltration, exhibited shorter overall survival. VEGF expression in EOC induced MDSCs, inhibited local immunity, and contributed to poor prognosis. This may explain the potential benefit of the combination therapeutic effects from VEFG inhibitor and various immunotherapies.

Beyond VEGF, there is literature addressing epithelial-mesenchymal transition (EMT). EMT often starts from the loss of E-cadherin (E-cad) to loosen the intercellular adhesions between the cancer cells. During the process of EMT, cancer cells acquire a more invasive phenotype. In the human normal ovary, the surface epithelium (OSE) is negative for E-cadherin (E-cad) expression and displays a baso-lateral distribution of Caveolin -1 (cav-1) [64]. Cav-1 expression is frequently lost or down-regulated in EOC, whereas E-cad is expressed de novo at least during early stages of tumor progression [64-66]. Down-regulation or loss of cav-1 might contribute significantly to the spread of tumor cells as opposed to cell to cell adhesion from the primary tumor [67]. Expression of cav-1 in the peritumoral stroma is associated with histological grade in ovarian serous tumors. However, Cav-1 expression was not an independent prognostic factor in survival analysis
[68]. Integrins are transmembrane receptors that facilitate cell-extracellular matrix adhesion and it recruit complex signaling events and integrin signaling regulates migration, invasion, proliferation, and survival through integrin-linked kinase (ILK), mitogen-activated protein kinase (MAPK), protein kinase B (PKB/Akt), or nuclear factor kappa B (NF- $k$ B) [69]. In EOC, about $40 \%$ (42 of 107) of patients with stage II-IV disease showed a5 $\beta 1$-integrin positive staining. The median survival of the patients with a5 $\beta 1$-integrin overexpression was significantly worse [70].

In addition, CD117 (c-kit) expression in fibroblast-like stromal cells in EOC was closely linked to histologic subtype, poor differentiation and stage, and it was significantly associated with poor PFS and OS [71].

Activation of the signal transducers and activators of transcription 3 (STAT3) pathway is associated with uncontrolled cell growth, through overexpression of oncogenes such as c-myc and cyclin $\mathrm{D}$ as well as pro-survival mechanisms in not just the tumor cells but also the cancer microenvironment [72]. STAT3 activating mutations have been associated with poorer response to first-line platinum-based therapy in patients treated for EOC, suggesting its role in chemotherapy resistance [73].

\section{3.b. Association with aging (in general)}

Aging affects the tumor microenvironment in various ways. Cellular senescence generates inflammation via alterations of their chemokines secretions, creating a recognizable pattern called the Senescence-associated secretory phenotype (SASP). This has been associated with multiple chronic diseases, including cancer. Multiple insults induce an activation of the p53 and p16 ${ }^{\text {ink4a }}$ tumor suppressor pathways and subsequent cell senescence. Senescent cells remain metabolically active. They alter the microenvironment, attract immune cells, and paradoxically induce malignant phenotypes in adjacent cells. The individual pro-inflammatory cytokines, chemokines, and proteases composing a SASP vary from tissue to tissue, but common proteins associated with SASP are TNF-a, IL-6, metalloproteinases (MMPs), Monocyte Chemoattractant Protein-1(MCP-1), and IGF-binding proteins [74]. SASP is thought to be the main driver of age-related inflammation. Cav-1 is a gatekeeper of cellular senescence and is overexpressed with aging. It has been associated with several chronic diseases such as cancer, diabetes, or atherosclerosis [75].

\section{3.c Association with age in EOC}

Our literature search did not identify any article exploring both in conjunction. 


\section{3.d Summary}

In summary, VEGF and its modulation have demonstrated a role in EOC. The microenvironment seems to play a key role in this setting and is the focus of intense research. Aging affects the microenvironment, as senescent cells create a SASP. While literature linking the two is still lacking, this appears a very promising venue to research, as well as large potential for therapeutic interventions.

\section{Chemotherapy resistance mechanisms}

\section{4.a Association with prognosis in EOC}

Chemotherapy resistance is an important factor in the management of and prognosis of EOC. For instance, it is well known that platinum refractory, resistant and sensitive group after completion of adjuvant treatment with paclitaxel and carboplatin have differences in their prognosis. In general, chemoresistance can be influenced by numerous factors pharmacokinetics to drug exposure, differences in cancer biology, immune responses and the microenvironment [76, 77]. This section will focus primarily on pharmacokinetics.

Primary resistance can occur as a result of factors that may prevent therapeutic concentrations of active drugs from being achieved, secondary to biological conditions affecting drug absorption, distribution, metabolism and elimination. These conditions can be affected by age and/or alterations in genes controlling drug metabolizing enzymes. Overexpression of ATP-Binding Cassette (ABC) drug transporters which results in multidrug resistance (MDR) has been shown to result in resistance to carboplatin and paclitaxel and ultimately chemoresistant disease. This and other ABC-related drug transporters have been shown be associated with disease recurrence and shorter OS in EOC [78-80].

EOC resistance to platinum-based chemotherapy has also been associated with activation of genes involved in the epithelial to mesenchymal transition (EMT). Marchini, et al utilized the molecular profiles to develop a genetic chemoresistance signature in advanced EOC patients. Biopsies were taken during the primary surgery prior to chemotherapy and again after several lines of chemotherapy. Of the genes utilized to develop the resistance signature, about $70 \%$ were involved with the TLR4, TGF- $\beta$ signaling pathway, remodeling of cell-cell and/or extracellular matrix interactions. The activation of these pathways are associated with EMT, and upregulation of several genes involved in this transition, including BMP and BAMBI along with miR-141, were also associated with worsening PFS and OS [81]. STAT3 has also been shown to be involved in EMT along with regulation by miRNA. Microarray assessment of microRNA expression levels in 57 patients with EOC across all stages and whom had all received first line platinum-based therapy found 7 miRNAs that were associated with platinum-resistance and 5 with differences in recurrence-free or overall survival [82].

Since the net result of chemoresistance is likely due to the interaction of multiple factors, genetic, epigenetic and proteomic methods have also been used to identify biomarkers. The value of identifying patients who are likely to respond to therapy is underscored by the heterogeneity of EOC. A proteomic assessment of EOC cell lines and 5 patient biopsy specimens identified 189 proteins associated with resistance to carboplatin and paclitaxel, including alpha-endonuclease, (ENOA), elongation factor Tu, mitochondrial (EFTU), glyceraldehyde-3phosphate dehydrogenase (G3P), stress-70 protein, mitochondrial (GRP75), apolipoprotein A-1 (APOA1), peroxiredoxin (PRDX2) and annexin A (ANXA) as candidate biomarkers of drug-resistant disease [83].

\section{4.b. Association with aging (in general)}

An increase in resistance to chemotherapy with age has been demonstrated in hematologic malignancies such as acute myelogenous leukemia, where P-glycoprotein is expressed at high levels in $73 \%$ of patients older than 55 years compared to $37 \%$ of younger patients, generating an MDR phenotype [84]. However, such a pattern has not been consistently demonstrated for solid tumors.

\section{4.c. Association with age in EOC}

The evidence to support biomarkers of chemoresistance specifically in older EOC patients is limited to primarily pharmacokinetic considerations. Patients $\geq 70$ years of age with EOC who are treated with either cisplatin or carboplatin in combination with paclitaxel can receive therapeutic doses with manageable adverse effects, especially when given with growth factor to prevent myelosuppression [3]. The impact of age on exposure to paclitaxel was specifically assessed as part of the CALGB 9762 trial with paclitaxel $175 \mathrm{mg} / \mathrm{m}^{2}$ over 3 hours. There was an age-related decrease in paclitaxel clearance $(p=0.007)$ and increase risk of neutropenia $(p=0.006)$ but no increase in hospitalizations [85]. Additional studies have also supported a decrease in paclitaxel clearance in patients $\geq 65$ years of age compared with those who are younger. As carboplatin undergoes renal elimination, area-under-the-curve (AUC)-based dosing includes correction for renal function. Empirical dose reductions for paclitaxel and/or carboplatin based on age are not recommended and age-related changes are more likely to result in higher rather than lower concentrations [86]. 


\section{4.d. Summary}

In summary, the etiology of chemoresistance in EOC is heterogeneous with few studies specifically linking age related factors to occurrence. While pharmacokinetic and pharmacodynamics factors influence drug exposure, they are likely to play a minimal role in the development of chemoresistance. Predictive tools that incorporate genomics, proteomics and transcriptomics may more accurately elucidate the diverse causes of chemoresistance and ongoing trials are needed to translate these findings into clinical decision making.

\section{DNA damage/Telomere,Cell cycle regulation/apoptosis/senescence}

\section{5.a Association with prognosis in EOC}

Platinum containing drugs, the main treatment for EOC, are agents with different effects leading to cell death. Platinum induces double-strand DNA breaks and subsequently activation of the DNA damage response (DDR). This may involve activation of a cell cycle checkpoint, commencement of transcriptional programs, execution of DNA repair, or when the damage is severe, initiation of apoptosis. For instance, mutations in BRCA1 and/or BRCA2 have been well described for their ability to predict responses to platinum agents and PARP inhibitors, and ultimately led to their approval for patients with ovarian cancer harboring deleterious mutations in these genes [87-89].

Up-regulation of DNA damage signaling and repair pathway may be an important cause of therapeutic resistance in EOC. Ataxia-telangiectasia mutated (ATM) and Ataxia-telangiectasia mutated and rad 3 related (ATR) are key proteins involved in DNA repair in response to DNA damaging chemotherapy [90]. And CHK1 and CHK2 have a role to relay the checkpoint signals from the proximal checkpoint kinases of the phosphatidylinositol 3-kinase family, particularly ATM and ATR [91]. Abdel-Rtah et al investigated ATM, ATR and DNA-PKcs (protein kinase C) protein expression and clinical outcome. High ATM protein expression was associated with platinum resistance $(p=0.017)$. High DNA PKcs associated with advanced stage $(p=0.018)$. Additionally, high ATM protein and mRNA, high DNA-PKcs protein and mRNA and high ATR protein were correlated with poor EOC specific survival [92]. However, retrospective analysis of polymorphisms in 5 DNA damage response genes (ATM, ATR, CHK1, CHK2, CDK12) were assessed in 240 patients with late stage EOC. OS and PFS were not affected by ATM, ATR or the CHK1/2 alterations. One genotype $(\mathrm{G} / \mathrm{G})$ of CDK12 was associated with shorter OS and PFS than A/A or A/G genotype, but predictive value was lost in the multivariate analysis [93]. Generally, the literature associating markers of DNA damage and telomere length with the prognosis of EOC is heterogeneous. A genome-wide association study (GWAS) meta-analysis with 2 independent sets of data showed no genome-wide association but two trends, namely, common variant rs8170 and rare variants in $A T G 2 B$ may be associated with EOC overall survival [94].

Telomeres shortening can activate the DNA damage response which can force cells into senescence and animal data has demonstrated a higher number of senescent cells in older animals compared with younger animals [95]. This shortening can also increase susceptibility to oncogenic processes through development of chromosomal alterations and instability [96]. Additionally, senescent cells have been shown to secrete pro-oncogenic substances including cytokines linked to inflammation and factors that disrupt the extracellular matrix [97]. Telomeres are maintained by the ribonucleoprotein complex telomerase, composed of two core components, the catalytic unit telomerase reverse transcriptase (hTERT), and an RNA component (hTERC). Telomerase has been shown to be activated in up to $90 \%$ of malignancies, including $76 \%$ of EOC, and this upregulation has been associated with shorter DFS in EOC [98]. Activation of human TERT(hTERT) is associated with the tumorigenic role of Akt. Lee at al evaluated the significance of Akt phosphorylation and hTERT expression on the prognosis in 92 EOC The DFS of patients exhibiting coexpression of pAkt and hTERT was poor compared with that of the other patients $(\mathrm{P}=0.013)$. Coexpression of pAkt and hTERT is a poor prognostic marker for EOC [99]. In the other hand, no association was found in the correlation of telomere length with EOC prognosis in a 1042 patient cohort study [100].

Cell cycle controlling proteins have received a lot of attention in oncology and aging in general. p16 ${ }^{\mathrm{INK} 4 \mathrm{~A}}$ and p53, both tumor suppressor proteins, co-regulate a plethora of transcripts in cell cycle [101]. More specific to EOC, a P21 WAF1, P27KIP1, TP53 and C-MYC analysis was performed in 204 EOC treated with platinum-based regimens. High P21WAF1 labeling index (LI) was an independent positive predictor of platinum-sensitive response $(P=0.02)$. OS was positively influenced by P21 ${ }^{\mathrm{WAF} 1} \mathrm{LI}(P=0.02)$ or by P21WAF1 plus P27KIP1 LI $(P=0.004)$ in the TP53-negative group only. Growth fraction was negatively associated with P21 ${ }^{\text {WAF1 }}$ and P27KIP1 indices in the TP53-negative group $(P=0.023$ and 0.008 , respectively), and these associations were borderline or lost in the TP53-positive group [102]. In another 
study of 47 EOC patients, Immunohistochemistry (IHC) staining was performed to evaluate HER2 and p16. p16 expression was associated with stage of disease (p0.04) and OS(p0.001) but HER2 was not associated with survival, histologic subtype or stage [103].

In the TCGA database, TP53 is mutated in $96 \%$ of EOC. However, different mutations can have very variable impacts on p53 function. Most mutations simply stabilize and inactivate P53, but some are actively oncogenic [104]. Because of that heterogeneity, studies have produced divergent results concerning the association of p53 with chemotherapy resistance in EOC [105].

\section{5.b. Association with aging (in general)}

It is well established that DNA damage, number of mutations and overall genomic instability increases with age. It has also been shown that there is high variation with respect to these occurrences between different tissues and they do not necessarily correlate with the proliferative nature of the specific tissue. Additionally, it has been shown that the efficiency of DNA repair mechanisms is indirectly related to age [106].Telomere length decreases with age. In humans, the average rate of decrease of leukocyte telomere length is 31 base pairs/year [107]. Telomere length is associated with years of healthy living, cancer prognosis, and human longevity [48].

P53 null mice develop a shortened life expectancy and increased tumor rates. However, a mouse model with a truncated p53 resulting in hyperactivation of p53 had a shorter lifespan but $0 \%$ tumor incidence compared to WT mice who had a $53 \%$ tumor incidence [108]. P16 ${ }^{\mathrm{INK} 4 \mathrm{~A}}$ is an inhibitor of CDK 4/6. Its level increases dramatically as tissue ages and is a biomarker of cellular senescence [109].

\section{5.c Association with age in EOC}

In the Elderly Women GINECO Trial 3 that evaluated the impact of geriatric covariates on the prognosis of EOC women aged 70 and over treated with carboplatin, peripheral blood telomere length was evaluated. Short telomere was associated with age, and with treatment completion rates $(\mathrm{p}=0.02)$, serious adverse events $(p=0.02)$, and a trend association with unplanned hospital admissions $(p=0.08)$, and OS $(p=0.06)$. There was a trend association with geriatric vulnerability parameters [110].

\section{5.d. Summary}

In summary, cell cycle control is critical in both cancer behavior and aging. Multiple molecular pathways are involved and more work needs to be done in linking aging and prognosis in EOC on that aspect. Telomere length and $\mathrm{p} 16^{\mathrm{INK} 4 \mathrm{~A}}$ do appear interesting primary targets of exploration with some evidence to support an association with prognosis.

\section{Metabolites}

Interest in cancer metabolism has been renewed due to our deeper mechanistic understanding of the interconnected signaling cascades and the identification of mutated genes and metabolic enzymes involved. These molecular insights have shown the possibility of developing novel anticancer treatments targeting tumor dependence on altered metabolic pathways. Here we limit discussion to Vitamin D and Insulin/IGF-1 pathway in association with EOC.

\subsection{Vitamin D}

\section{1.a Association with prognosis in EOC}

Many epidemiological studies have suggested that people with low levels of 25-hydroxyvitamin D $(25(\mathrm{OH}) \mathrm{D}$ have increased risk of death [111]. Significant associations between circulating 25(OH)D levels at the time of diagnosis and the outcomes for cancer patients were reported on 17,332 cancer patients [112]. Pittas et al. found that intake of ordinary doses of vitamin D supplements was associated with a modest decrease in total mortality [113]. Wong et al. found 33\% increase in cancer-specific mortality for every $30 \mathrm{nmol} / \mathrm{L}$ reduction in serum $25(\mathrm{OH})$ D concentrations in elderly women [114]. The Australian Ovarian Cancer Study group reported that the higher serum $25(\mathrm{OH}) \mathrm{D}$ concentrations at diagnosis were associated with longer survival, but they did not find significant association with PFS or for $25(\mathrm{OH}) \mathrm{D}$ measured after primary treatment [115]. In another study, women with recurrent EOC were found to have lower levels of $25(\mathrm{OH}) \mathrm{D}$ compared to women with stable EOC [116].

\section{1.b Association with aging (in general)}

The majority of people with age 70 and older have decreased levels of serum 25(OH)D [117] in association to several factors: female gender, dark skin pigmentation, reduced capacity of skin production, reduced sun exposure, decreased intake of supplements, obesity, malabsorption disorders, reduced renal function, and certain medications. The average 70 year old individuals have a $75 \%$ reduced capacity to produce vitamin D compared to people in their twenties due to the reduction of 7-dehydrocholesterol [118]. One of the links between vitamin $\mathrm{D}$ and survival in elderly could be association between vitamin $\mathrm{D}$ and leukocyte telomere length, a marker of aging-related diseases, increased oxidative 
stress, and inflammation. Subjects with low vitamin D levels and high CRP serum concentrations had the shortest leukocyte telomere length, indicating a higher cumulative burden of oxidative stress and inflammation [119]. De Vita et al. evaluated the relationship between vitamin $\mathrm{D}$ levels and inflammatory cytokines in 867 patients over 65 years old. They observed that in older individuals $25(\mathrm{OH}) \mathrm{D}$ concentration is independently and inversely associated with IL-6 and positively with sIL6r, suggesting a potential anti-inflammatory role for vitamin D in older individuals [120].

\subsection{Insulin/IGF-1 pathway}

\section{2.a Association with prognosis in EOC}

The Insulin-like growth factor (IGF) system plays important role in regulation of normal cell growth and development, and tissue repair. It is comprised of two peptide ligands (IGF1 and IGF2) which are structurally similar to insulin, a family of six different IGF-binding proteins (IGFBPs, 1-6), and two membrane-spanning tyrosine kinase receptors (IGF1R and IGF2R). In cancer cells, it suppresses apoptosis and promotes cell cycle progression and angiogenesis [121]. IGFBPs play a complex role in physiological system which is mainly responsible for protecting IGF in circulation and delivering them to their target site. Increased IGF1R activity increases carcinogenesis, metastatic potential, and resistance to chemotherapy drugs [122]. In many cancer types, overexpression of IGF2 has been observed and it is associated with a poor prognosis [123, 124].

In ovarian cancer, Brokaw et al reported that IGF-I is involved in ovarian cancer progression in 215 patients with EOC and particularly, demonstrated that high serum levels of free IGF1 were associated with increased risk of cancer progression. These findings support that free IGF-I plays a more important role in the disease [125]. Yunusova et al also reported that the level of IGF1 in ascites was shown to be an independent predictor of objective clinical response to neoadjuvant chemotherapy in 59 patients with EOC [126]. The role of IGF2 has also been evaluated in EOC in multiple studies. High IGF2 gene expression is associated with advanced stage disease, higher tumor grade, and is independent predictor of poor survival in patients with EOC [127-129].

\section{2.b Association with aging (in general)}

Free IGF-1 levels were found to be increased in subjects above the age of 70 [130]. It has been reported that elderly patients may also have a small rise in the number of IGF type 1 receptors per cell [131].

\subsection{Summary}

In summary, as the prevalence of low Vitamin D levels increases in an aging population and is associated with worse cancer prognosis, it may explain some of the link of age with worse prognosis, although this has not been formally demonstrated. This could be targeted with a simple intervention. The role of the insulin/IGF-1pathway is more complex to assess.

\section{Epigenetics and- miRNAs}

\subsection{Epigenetics}

\section{1.a Association with prognosis in EOC}

The use of transcriptomics and clinical data analyzed by a computational method (PSFinder) was employed to risk-stratify patients with high-grade serous EOC. One good and two poor-survival groups were identified from 180 patients and then validated in 8 independent data sets, including a prospective cohort. The groups were characterized by 61 different transcript isoforms with the two poor prognostic groups being enriched for increased hypermethylation and alterations in genes related to stroma. Though this method was validated in patients of all ages, the median age was 58-65 across the cohorts with ranges up to 89 years of age [132]. The DNA methylation pattern associated with the long non-coding RNA HOX transcript antisense intergenic RNA (HOTAIR) has been associated with resistance to carboplatin and poor prognosis in EOC [133].

\section{1.b Association with aging (in general)}

DNA methylation is affected by aging with some genes becoming hypermethylated and others hypomethylated. The methylation of several genes is so closely correlated with aging that "epigenetic clocks" have been proposed to measure biological aging that perform well when compared with other markers of biological aging such as telomere length [134]. The methylation age measured in peripheral blood mononuclear cells (PBMC) has been associated with the risk of developing lung cancer in the Women' Health Initiative Study [135].

\section{1.c Association with age in EOC}

In one study, patients with an active ovarian cancer had changes in PBMC methylation that were similar to those induced by aging. Multiple age-associated methylation changes were found in patients with recurrent ovarian cancer but not in patients in clinical remission nor healthy controls. The genes affected are associated with hematopoietic lineage and immune function [136]. As this was a cross-sectional study, it is unclear however whether 
these changes were simply reactive or whether they contributed to the relapse.

\subsection{MicroRNAs}

MicroRNAs (miRNAs) are small double stranded noncoding RNAs approximately 19-25 nucleotide in length. The main function of miRNAs is the regulation of gene expression in a post transcriptional manner [137]. MiRNAs are possibly produced by all mammalian cell types and appear to have a regulatory role in the magnitude of cellular processes. It is predicted that the human genome encodes thousands of miRNAs that collectively target the expression of more than 19,000 human genes [138]. Due to their abundance and regulatory function over numerous processes, it is no surprise that miRNA deregulation has been implicated in the development and/or progression of many human cancers. The typical genome of EOC is characterized by multitudes of chromosomal amplifications and deletions. Data from The Cancer Genome Atlas (TCGA) suggests that numerous miRNAs are located within these genomic regions of high variability in EOC [139] suggesting that miRNA may play a large role in EOC pathogenicity. Multiple studies have reported the possible roles of various miRNA in EOC development, progression, response to therapy, recurrence, and patient outcome. For comprehensive reviews, please see Katz et al, and Prahm et al, 2015 [140, 141]. Similarly, miRNA expression patterns appear to change during aging and most likely play a role in age related ailments (for review, see [142]). Interestingly, the overall abundance of miRNA transcripts are diminished in both cancer and during aging $[143,144]$.

\section{2.a Association with age in EOC}

Given the tremendous number of miRNA alterations that have been described in the EOC and the aging literature, we will focus this section on the common alterations that have been reported. After compiling the data reported in several review articles, we identified a list of miRNA commonly altered in both aging and EOC. While this cannot be considered an exhaustive list, we identified 13 miRNA associated with both aging and EOC, including those upregulated; miR-21, miR-126, miR-92a, miR-142-3p, and those downregulated; miR-19b, miR-22, miR-24, miR-146a, miR-150, miR-155, miR-25-3p, miR-106b, miR-191 [48, 140-142, 145-147]. Each of these miRNA may be involved in the regulation of a multitude of cellular processes, context dependent, or cell type specific. However, when evaluated as a group the commonality between these miRNA are regulatory roles in the control of immune function and inflammatory response.
MiRNA upregulated in EOC and aging: MiR-21 expression is most commonly associated with inflammation and has been suggested to be a biomarker of 'inflammaging' [148]. The expression of miR-92a is elevated in a variety of cancer types and may positively regulate the differentiation of pro-inflammatory Th17, T helper cells [149]. Mir-126 has been implicated in tumor progression and may promote the suppressive function of regulatory $\mathrm{T}$ cells [150]. Further, miR-126 has been reported to promote or suppress inflammation depending on the context $[151,152]$. MiR-142-3p has been associated with the pro-inflammatory function of dendritic cells in systemic lupus erythematosus [153], and in collaboration with miR-24 and miR-30b may interfere with macrophage and dendritic cell antigen processing and presentation [154].

MiRNA downregulated in EOC and aging: MiR-19b has been reported to modulate the inflammatory response [155-157], although this function of miR-19b may be context dependent. Philippe et al., found that miR-19b directly targets Toll-Like Receptor 2 (TLR2) mRNA and thus may function as a negative regulator or inflammation in Rheumatoid fibroblast-like synoviocytes [157]. Similarly, Cheng et al. reported that miR-19b suppressed the inflammatory response in intestinal epithelial cells by inhibition of Suppressor of Cytokine Signaling 3 (SOCS3) [155]. In contrast, Gantier et al. reported a positive regulation of proinflammatory cytokines by miR-19b in bone marrow derived macrophage and that overexpression of miR-19b resulted in increased basal inflammation in fibroblast-like synoviocytes [156]. MiR-22 was reported to promote inflammation in endothelial cells through a mechanism believed to involve miR-22 inhibition of ICAM-1 [158, 159]. In contrast, miR-24 and miR-106b may negatively regulate inflammation associated with the allergic response in $\mathrm{T}$ cells and bone marrow derived dendritic cells, respectively $[160,161]$. In conjunction with miR-93, miR-106b also plays a role in the negative regulation of PDL-1 expression and the expression of the leukocyte chemoattractant, CXCL12 [162]. Depletion of miR-150 has been shown to impair the function of CD8+ T cells [163] and increase the secretion of inflammatory cytokines by CD4+ $\mathrm{T}$ cells [164]. MiR-146a and miR-155 appear to play multiple roles in the differentiation and maturation of immune cell lineages [165-168] and may have context dependent regulatory control in both the initiation and suppression of inflammatory responses [169-171]. Taken together, the altered expression of miRNAs common to OVCA and aging suggest that both situations may be characterized by a deregulation in both immune function and inflammatory response. 
Several miRNAs show aging-associated expression changes [48]. Animal studies also show changes in ovarian microRNA profile with aging [146].

In summary, each of these miRNA may be involved in the regulation of a multitude of cellular processes, context dependent, or cell type specific. However, when evaluated as a group the commonality between these miRNA are regulatory roles in the control of immune function and inflammatory response. This may further support the links established between inflammation, age, and EOC prognosis mentioned in section 2.

\subsection{Summary}

In summary, methylation changes occur in both ovarian cancer and aging. Some aging-similar methylation patterns have been observed in a study of patients with active ovarian cancer, but more work needs to be done to understand its significance. Some miRNA have been report to be associated with both ovarian cancer and aging and are related to the control of immune function and inflammation.

\section{Mitochondria related gene alterations, oxidation mechanisms}

\section{8.a Association with prognosis in EOC}

As neoplastic cells accumulate in three-dimensional multicellular masses, local low nutrient and oxygen levels trigger the growth of new blood vessels into the neoplasm. The imperfect neovasculature in the tumor bed is poorly formed and inefficient and hence poses nutrient and hypoxic stress [172]. Hypoxic adaptation by cancer cells is essential for survival and progression of a tumor. The role of hypoxia in cancer cell metabolism is discussed in the context of tumorigenesis [173]. Oxidative stress is a key contributing factor in aging. Some work on mitochondria, oxidation and prognosis is available in EOC.

Kong et al. analyzed single nucleotide polymorphisms (SNPs) in the displacement loop (D-loop) of mitochondrial DNA (mtDNA) in patients with EOC [174]. They found that the alleles 309T and $324 \mathrm{G}$ were associated with a shorter post-operative survival. The mitochondrial transcription factor $\mathrm{A}$ ( mtTFA) that helps transcription and maintenance of the integrity of mitochondrial DNA, can also be expressed in the cell nucleus in addition to expressed in mitochondria. In a univariate analysis of patients with serous EOC, the $56.7 \%$ who were positive for nuclear expression of mtTFA had a worse 5 year survival than the others ( $32 \%$ vs $42 \%, p=0.021)[5$, 175].
Hypoxia-inducible factor (HIF)-1a expression plays an important role in tumor progression and metastasis. Meta-analysis from 24 studies indicated that HIF-1a is related to the malignant degree, FIGO stage, histological grade, lymph node metastasis and 5-year survival rate (OR=11.46 (95 \% CI, 3.43-38.29); $\mathrm{P}<0.0001)$ of EOC [176].

\section{8.b Association with aging (in general)}

Oxidative stress is recognized as one of the contributing mechanisms to aging. Links have been proposed between chronic oxidative stress, inflammaging and immunosenescence [177]. Oxidative stress increases apoptosis due to the accumulation of oxidatively damaged biomolecules and contributes to the decrease of the lymphocyte pool. A major component of the antitumor response is tumor antigen-specific effector $\mathrm{T}$ cells. With vaccines, $\mathrm{T}$ cells become metabolically highly active and need glucose uptake to support glycolysis for biogenesis and ATP production. In this they are in direct competition with cancer cells. Metabolic fitness declines upon aging. Mitochondrial functions decrease due to accumulating mitochondrial DNA mutations, decreasing further the ability of TILs to compete for glucose in the tumor microenvironment [178]. Oxidative stress also leads to mitochondrial fragmentation and aging [179]. Age-dependent obesity is associated with a decline in mitochondrial complex IV activity, driven by HIF-1a [180].

\section{8.c Association with age in EOC}

As HIF-1a expression is associated both with EOC survival and age-dependent obesity, it is tempting to explore a clinical correlation with prognosis. However, studies on the association of BMI and EOC prognosis show a somewhat complex association that will need further elucidation [181, 182].

\section{8.d Summary}

In summary, while oxidative stress offers some hypothetical links between aging and EOC prognosis, little evidence is available so far to test this hypothesis.

\section{General conclusion}

We reviewed multiple potential culprits to explain the poor prognosis of elderly patients with EOC, from cellular immunity, inflammation/cytokine changes, micro-environment, chemotherapy resistance, cell cycle regulation/apoptosis/ senescence, and metabolites to novel gene alterations associated with the aging process. We found that very few studies have assessed the question directly. Since 
this constitutes to our knowledge the first comprehensive effort at assembling evidence on the biological mechanisms that may underlie the worsening prognosis of ovarian cancer with aging, this should be viewed as a survey of the state of the field. Oncogeriatric research has shown that the impact of biological and physiological aging varies from tumor to tumor: for example, acute myelogenous leukemia arises from earlier stem cells in older patients; colon cancer is more likely right-sided; breast cancer more likely hormone receptor positive. Therefore evidence specific to ovarian cancer needs to be developed. We hope our effort will contribute in giving a survey and insights into which mechanisms appear the most promising to explore. Some limitations apply. As this is not a formal systematic review, we may have missed other potential mechanisms. Our group however combined experts in geriatric oncology, ovarian cancer, and pharmacology, ensuring that most plausible mechanisms were researched and either included or discarded for lack of relevant evidence. Among the mechanisms affecting both aging and EOC prognosis, those involving immunity and inflammation appear those whose potential is supported by the strongest parallel evidence, although our review highlighted the potential of other mechanisms. All will have to be tested in studies exploring jointly the correlation of these mechanisms with age and EOC prognosis.

\section{Acknowledgments}

This research was supported by grants D2015-001 and D2015-014 from the Kay Yow Cancer Fund/V Foundation.

\section{Abbreviations}

\section{EOC: Epithelial ovarian cancer.}

\section{Competing Interests}

The authors have declared that no competing interest exists.

\section{References}

1. Siegel RL, Miller KD, Jemal A. Cancer statistics, 2017. CA: A Cancer Journal for Clinicians. 2017; 67: 7-30.

2. [Internet] SEER. Annual Report to the Nation 2018: National Cancer Statistics. https://seer.cancer.gov/; 2018.

3. Hilpert F, du Bois A, Greimel ER, Hedderich J, Krause G, Venhoff L, et al. Feasibility, toxicity and quality of life of first-line chemotherapy with platinum/paclitaxel in elderly patients aged >or=70 years with advanced ovarian cancer--a study by the AGO OVAR Germany. Ann Oncol. 2007; 18: 282-7.

4. Munoz KA, Harlan LC, Trimble EL. Patterns of care for women with ovarian cancer in the United States. J Clin Oncol. 1997; 15: 3408-15.

5. Petignat P, Fioretta G, Verkooijen HM, Vlastos AT, Rapiti E, Bouchardy C, et al. Poorer survival of elderly patients with ovarian cancer: a population-based study. Surg Oncol. 2004; 13: 181-6.

6. Todd S, Robertson SE, Xiong Y, Extermann M, Wenham RM, Chon HS. Impact of age, comorbidity, and treatment on survival in elderly women with advanced epithelial ovarian cancer. Journal of Clinical Oncology. 2017; 35: e17072-e.
7. Shield K, Ackland ML, Ahmed N, Rice GE. Multicellular spheroids in ovarian cancer metastases: Biology and pathology. Gynecologic oncology. 2009; 113: 143-8.

8. Hwang WT, Adams SF, Tahirovic E, Hagemann IS, Coukos G. Prognostic significance of tumor-infiltrating $\mathrm{T}$ cells in ovarian cancer: a meta-analysis. Gynecologic oncology. 2012; 124: 192-8.

9. Zhang L, Conejo-Garcia JR, Katsaros D, Gimotty PA, Massobrio M, Regnani G, et al. Intratumoral $\mathrm{T}$ cells, recurrence, and survival in epithelial ovarian cancer. N Engl J Med. 2003; 348: 203-13.

10. Corthay A. How do regulatory T cells work? Scand J Immunol. 2009; 70: 326-36.

11. Woo EY, Chu CS, Goletz TJ, Schlienger K, Yeh H, Coukos G, et al. Regulatory CD4(+)CD25(+) T cells in tumors from patients with early-stage non-small cell lung cancer and late-stage ovarian cancer. Cancer Res. 2001; 61: 4766-72.

12. Li X, Ye DF, Xie X, Chen HZ, Lu WG. Proportion of CD4+CD25+ regulatory T cell is increased in the patients with ovarian carcinoma. Cancer Invest. 2005; 23: 399-403.

13. Preston CC, Maurer MI, Oberg AL, Visscher DW, Kalli KR, Hartmann LC, et al. The ratios of CD8+ T cells to CD4+CD25+ FOXP3+ and FOXP3- T cells correlate with poor clinical outcome in human serous ovarian cancer. PLoS One. 2013; 8: e80063.

14. Shah CA, Allison KH, Garcia RL, Gray HJ, Goff BA, Swisher EM. Intratumoral $\mathrm{T}$ cells, tumor-associated macrophages, and regulatory $\mathrm{T}$ cells: association with p53 mutations, circulating tumor DNA and survival in women with ovarian cancer. Gynecologic oncology. 2008; 109: 215-9.

15. Sato E, Olson SH, Ahn J, Bundy B, Nishikawa H, Qian F, et al. Intraepithelial $\mathrm{CD} 8+$ tumor-infiltrating lymphocytes and a high $\mathrm{CD} 8+$ /regulatory $\mathrm{T}$ cell ratio are associated with favorable prognosis in ovarian cancer. Proc Natl Acad Sci US A. 2005; 102: 18538-43.

16. Wolf D, Wolf AM, Rumpold H, Fiegl H, Zeimet AG, Muller-Holzner E, et al. The expression of the regulatory $\mathrm{T}$ cell-specific forkhead box transcription factor FoxP3 is associated with poor prognosis in ovarian cancer. Clin Cancer Res. 2005; 11: 8326-31.

17. Curiel TJ, Coukos G, Zou L, Alvarez X, Cheng P, Mottram P, et al. Specific recruitment of regulatory $\mathrm{T}$ cells in ovarian carcinoma fosters immune privilege and predicts reduced survival. Nat Med. 2004; 10: 942-9.

18. Fridman WH, Pages F, Sautes-Fridman C, Galon J. The immune contexture in human tumours: impact on clinical outcome. Nat Rev Cancer. 2012; 12: 298-306.

19. Iwai M, Kobayashi M, Tamura K, Ishii Y, Yamada H, Niwa M. Direct identification of disulfide bond linkages in human insulin-like growth factor I (IGF-I) by chemical synthesis. J Biochem. 1989; 106: 949-51.

20. Santoiemma PP, Reyes C, Wang LP, McLane MW, Feldman MD, Tanyi JL, et al. Systematic evaluation of multiple immune markers reveals prognostic factors in ovarian cancer. Gynecologic oncology. 2016; 143: $120-7$.

21. Nguyen LT, Ohashi PS. Clinical blockade of PD1 and LAG3--potential mechanisms of action. Nat Rev Immunol. 2015; 15: 45-56.

22. Yao S, Zhu Y, Chen L. Advances in targeting cell surface signalling molecules for immune modulation. Nat Rev Drug Discov. 2013; 12: 130-46.

23. Maccalli C, Volonte A, Cimminiello C, Parmiani G. Immunology of cancer stem cells in solid tumours. A review. Eur J Cancer. 2014; 50: 649-55.

24. Tse BW, Collins A, Oehler MK, Zippelius A, Heinzelmann-Schwarz VA. Antibody-based immunotherapy for ovarian cancer: where are we at? Ann Oncol. 2014; 25: 322-31.

25. Hamanishi J, Mandai M, Abiko K, Matsumura N, Baba T, Yoshioka Y, et al. The comprehensive assessment of local immune status of ovarian cancer by the clustering of multiple immune factors. Clin Immunol. 2011; 141: 338-47.

26. Hamanishi J, Mandai M, Iwasaki M, Okazaki T, Tanaka Y, Yamaguchi K, et al. Programmed cell death 1 ligand 1 and tumor-infiltrating CD8+ T lymphocytes are prognostic factors of human ovarian cancer. Proc Natl Acad Sci U S A. 2007; 104: 3360-5.

27. Abiko K, Mandai M, Hamanishi J, Yoshioka $\mathrm{Y}$, Matsumura N, Baba T, et al. PD-L1 on tumor cells is induced in ascites and promotes peritoneal dissemination of ovarian cancer through CTL dysfunction. Clin Cancer Res. 2013; 19: 1363-74.

28. Hirohashi Y, Torigoe T, Mariya T, Kochin V, Saito T, Sato N. HLA class I as a predictor of clinical prognosis and CTL infiltration as a predictor of chemosensitivity in ovarian cancer. Oncoimmunology. 2015; 4: e1005507.

29. Garrido F, Cabrera T, Aptsiauri N. "Hard" and "soft" lesions underlying the HLA class I alterations in cancer cells: implications for immunotherapy. Int J Cancer. 2010; 127: 249-56.

30. Mariya $T$, Hirohashi $Y$, Torigoe $T$, Asano $T$, Kuroda $T$, Yasuda $K$, et al Prognostic impact of human leukocyte antigen class I expression and association of platinum resistance with immunologic profiles in epithelial ovarian cancer. Cancer Immunol Res. 2014; 2: 1220-9.

31. Nielsen JS, Sahota RA, Milne K, Kost SE, Nesslinger NJ, Watson PH, et al. CD20+ tumor-infiltrating lymphocytes have an atypical CD27- memory phenotype and together with CD8+ T cells promote favorable prognosis in ovarian cancer. Clin Cancer Res. 2012; 18: 3281-92.

32. Dong HP, Elstrand MB, Holth A, Silins I, Berner A, Trope CG, et al. NK- and B-cell infiltration correlates with worse outcome in metastatic ovarian carcinoma. Am J Clin Pathol. 2006; 125: 451-8.

33. Milne K, Kobel M, Kalloger SE, Barnes RO, Gao D, Gilks CB, et al. Systematic analysis of immune infiltrates in high-grade serous ovarian cancer reveals 
CD20, FoxP3 and TIA-1 as positive prognostic factors. PLoS One. 2009; 4: e6412.

34. Li K, Mandai M, Hamanishi J, Matsumura N, Suzuki A, Yagi H, et al. Clinical significance of the NKG2D ligands, MICA/B and ULBP2 in ovarian cancer: high expression of ULBP2 is an indicator of poor prognosis. Cancer Immunol Immunother. 2009; 58: 641-52.

35. Leffers N, Daemen T, Helfrich W, Boezen HM, Cohlen BJ, Melief CJ, et al. Antigen-specific active immunotherapy for ovarian cancer. Cochrane Database Syst Rev. 2014: Cd007287.

36. Berek J, Taylor P, McGuire W, Smith LM, Schultes B, Nicodemus CF. Oregovomab maintenance monoimmunotherapy does not improve outcomes in advanced ovarian cancer. J Clin Oncol. 2009; 27: 418-25.

37. Sabbatini P, Harter P, Scambia G, Sehouli J, Meier W, Wimberger P, et al. Abagovomab as maintenance therapy in patients with epithelial ovarian cancer: a phase III trial of the AGO OVAR, COGI, GINECO, and GEICO--the MIMOSA study. J Clin Oncol. 2013; 31: 1554-61.

38. Pawelec G, Derhovanessian E, Larbi A. Immunosenescence and cancer. Crit Rev Oncol Hematol. 2010; 75: 165-72.

39. Bigley AB, Spielmann G, LaVoy EC, Simpson RJ. Can exercise-related improvements in immunity influence cancer prevention and prognosis in the elderly? Maturitas. 2013; 76: 51-6.

40. Clendenen TV, Lundin E, Zeleniuch-Jacquotte A, Koenig KL, Berrino F, Lukanova A, et al. Circulating inflammation markers and risk of epithelial ovarian cancer. Cancer Epidemiol Biomarkers Prev. 2011; 20: 799-810.

41. Dobrzycka B, Terlikowski SJ, Kowalczuk O, Kinalski M. Circulating levels of TNF-alpha and its soluble receptors in the plasma of patients with epithelial ovarian cancer. Eur Cytokine Netw. 2009; 20: 131-4.

42. Giuntoli RL, 2nd, Webb TJ, Zoso A, Rogers O, Diaz-Montes TP, Bristow RE, et al. Ovarian cancer-associated ascites demonstrates altered immune environment: implications for antitumor immunity. Anticancer Res. 2009; 29: 2875-84.

43. Maccio A, Madeddu C. Inflammation and ovarian cancer. Cytokine. 2012; 58: 133-47.

44. Thibault B, Castells M, Delord JP, Couderc B. Ovarian cancer microenvironment: implications for cancer dissemination and chemoresistance acquisition. Cancer Metastasis Rev. 2014; 33: 17-39.

45. Stone RL, Nick AM, McNeish IA, Balkwill F, Han HD, Bottsford-Miller J, et al. Paraneoplastic thrombocytosis in ovarian cancer. N Engl J Med. 2012; 366: 610-8.

46. Kolomeyevskaya N, Eng KH, Khan AN, Grzankowski KS, Singel KL, Moysich $\mathrm{K}$, et al. Cytokine profiling of ascites at primary surgery identifies an interaction of tumor necrosis factor-alpha and interleukin-6 in predicting reduced progression-free survival in epithelial ovarian cancer. Gynecol Oncol. 2015; 138: 352-7.

47. Matte I, Lane D, Laplante C, Rancourt C, Piche A. Profiling of cytokines in human epithelial ovarian cancer ascites. Am J Cancer Res. 2012; 2: 566-80.

48. Pallis AG, Hatse S, Brouwers B, Pawelec G, Falandry C, Wedding U, et al. Evaluating the physiological reserves of older patients with cancer: the value of potential biomarkers of aging? J Geriatr Oncol. 2014; 5: 204-18.

49. Monti D, Ostan R, Borelli V, Castellani G, Franceschi C. Inflammaging and human longevity in the omics era. Mech Ageing Dev. 2016.

50. Kovtonyuk LV, Fritsch K, Feng X, Manz MG, Takizawa H. Inflamm-Aging of Hematopoiesis, Hematopoietic Stem Cells, and the Bone Marrow Microenvironment. Front Immunol. 2016; 7: 502.

51. Maggio M, Guralnik JM, Longo DL, Ferrucci L. Interleukin-6 in aging and chronic disease: a magnificent pathway. J Gerontol A Biol Sci Med Sci. 2006; 61: 575-84.

52. Zhu S, Patel KV, Bandinelli S, Ferrucci L, Guralnik JM. Predictors of interleukin-6 elevation in older adults. J Am Geriatr Soc. 2009; 57: 1672-7.

53. Studenski S, Perera S, Patel K, Rosano C, Faulkner K, Inzitari M, et al. Gait speed and survival in older adults. Jama. 2011; 305: 50-8.

54. Puzianowska-Kuznicka M, Owczarz M, Wieczorowska-Tobis K, Nadrowski P, Chudek J, Slusarczyk P, et al. Interleukin-6 and C-reactive protein, successful aging, and mortality: the PolSenior study. Immun Ageing. 2016; 13: 21.

55. Harris TB, Ferrucci L, Tracy RP, Corti MC, Wacholder S, Ettinger WH, Jr., et al. Associations of elevated interleukin-6 and C-reactive protein levels with mortality in the elderly. Am J Med. 1999; 106: 506-12.

56. Stepanova M, Rodriguez E, Birerdinc A, Baranova A. Age-independent rise of inflammatory scores may contribute to accelerated aging in multi-morbidity. Oncotarget. 2015; 6: 1414-21.

57. Cohen HJ, Harris T, Pieper CF. Coagulation and activation of inflammatory pathways in the development of functional decline and mortality in the elderly. Am J Med. 2003; 114: 180-7.

58. Varadhan R, Yao W, Matteini A, Beamer BA, Xue QL, Yang H, et al. Simple biologically informed inflammatory index of two serum cytokines predicts 10 year all-cause mortality in older adults. J Gerontol A Biol Sci Med Sci. 2014; 69: 165-73.

59. Hefler LA, Concin N, Hofstetter G, Marth C, Mustea A, Sehouli J, et al. Serum $\mathrm{C}$-reactive protein as independent prognostic variable in patients with ovarian cancer. Clin Cancer Res. 2008; 14: 710-4.

60. Yamamoto S, Konishi I, Tsuruta Y, Nanbu K, Mandai M, Kuroda H, et al. Expression of vascular endothelial growth factor (VEGF) during folliculogenesis and corpus luteum formation in the human ovary. Gynecological endocrinology: the official journal of the International Society of Gynecological Endocrinology. 1997; 11: 371-81.
61. Shen GH, Ghazizadeh M, Kawanami O, Shimizu H, Jin E, Araki T, et al. Prognostic significance of vascular endothelial growth factor expression in human ovarian carcinoma. Br J Cancer. 2000; 83: 196-203.

62. Pujade-Lauraine E, Hilpert F, Weber B, Reuss A, Poveda A, Kristensen G, et al. Bevacizumab combined with chemotherapy for platinum-resistant recurrent ovarian cancer: The AURELIA open-label randomized phase III trial. J Clin Oncol. 2014; 32: 1302-8.

63. Horikawa N, Abiko K, Matsumura N, Hamanishi J, Baba T, Yamaguchi K, et al. Expression of Vascular Endothelial Growth Factor in Ovarian Cancer Inhibits Tumor Immunity through the Accumulation of Myeloid-Derived Suppressor Cells. Clin Cancer Res. 2017; 23: 587-99.

64. Wiechen K, Diatchenko L, Agoulnik A, Scharff KM, Schober H, Arlt K, et al. Caveolin-1 is down-regulated in human ovarian carcinoma and acts as a candidate tumor suppressor gene. Am J Pathol. 2001; 159: 1635-43.

65. Bagnoli M, Tomassetti A, Figini M, Flati S, Dolo V, Canevari S, et al. Downmodulation of caveolin-1 expression in human ovarian carcinoma is directly related to alpha-folate receptor overexpression. Oncogene. 2000; 19: 4754-63.

66. Marques FR, Fonsechi-Carvasan GA, De Angelo Andrade LA, Bottcher-Luiz F. Immunohistochemical patterns for alpha- and beta-catenin, E- and N-cadherin expression in ovarian epithelial tumors. Gynecologic oncology. 2004; 94: 16-24.

67. Miotti S, Tomassetti A, Facetti I, Sanna E, Berno V, Canevari S. Simultaneous expression of caveolin-1 and E-cadherin in ovarian carcinoma cells stabilizes adherens junctions through inhibition of src-related kinases. Am J Pathol. 2005; 167: 1411-27.

68. Sayhan S, Diniz G, Karadeniz T, Ayaz D, Kahraman DS, Gokcu M, et al. Expression of caveolin-1 in peritumoral stroma is associated with histological grade in ovarian serous tumors. Ginekol Pol. 2015; 86: 424-8.

69. Stupp R, Ruegg C. Integrin inhibitors reaching the clinic. J Clin Oncol. 2007; 25 : 1637-8.

70. Sawada K, Mitra AK, Radjabi AR, Bhaskar V, Kistner EO, Tretiakova M, et al. Loss of E-cadherin promotes ovarian cancer metastasis via alpha 5-integrin, which is a therapeutic target. Cancer Res. 2008; 68: 2329-39.

71. Huang R, Wu D, Yuan Y, Li X, Holm R, Trope CG, et al. CD117 expression in fibroblasts-like stromal cells indicates unfavorable clinical outcomes in ovarian carcinoma patients. PLoS One. 2014; 9: e112209.

72. Darnell JE, Jr. STATs and gene regulation. Science. 1997; 277: 1630-5.

73. Permuth-Wey J, Fulp WJ, Reid BM, Chen Z, Georgeades C, Cheng JQ, et al. STAT3 polymorphisms may predict an unfavorable response to first-line platinum-based therapy for women with advanced serous epithelial ovarian cancer. Int J Cancer. 2016; 138: 612-9.

74. Tchkonia T, Zhu Y, van Deursen J, Campisi J, Kirkland JL. Cellular senescence and the senescent secretory phenotype: therapeutic opportunities. J Clin Invest. 2013; 123: 966-72.

75. Nguyen KC, Cho KA. Versatile Functions of Caveolin-1 in Aging-related Diseases. Chonnam Med J. 2017; 53: 28-36.

76. Au KK, Josahkian JA, Francis JA, Squire JA, Koti M. Current state of biomarkers in ovarian cancer prognosis. Future Oncol. 2015; 11: 3187-95.

77. Hiss D. Optimizing molecular-targeted therapies in ovarian cancer: the renewed surge of interest in ovarian cancer biomarkers and cell signaling pathways. J Oncol. 2012; 2012: 737981.

78. Baekelandt MM, Holm R, Nesland JM, Trope CG, Kristensen GB. P-glycoprotein expression is a marker for chemotherapy resistance and prognosis in advanced ovarian cancer. Anticancer Res. 2000; 20: 1061-7.

79. Johnatty SE, Beesley J, Paul J, Fereday S, Spurdle AB, Webb PM, et al. ABCB1 (MDR 1) polymorphisms and progression-free survival among women with ovarian cancer following paclitaxel/carboplatin chemotherapy. Clin Cancer Res. 2008; 14: 5594-601.

80. Ween MP, Armstrong MA, Oehler MK, Ricciardelli C. The role of ABC transporters in ovarian cancer progression and chemoresistance. Crit Rev Oncol Hematol. 2015; 96: 220-56.

81. Marchini S, Fruscio R, Clivio L, Beltrame L, Porcu L, Fuso Nerini I, et al Resistance to platinum-based chemotherapy is associated with epithelial to mesenchymal transition in epithelial ovarian cancer. Eur J Cancer. 2013; 49: 520-30.

82. Eitan R, Kushnir M, Lithwick-Yanai G, David MB, Hoshen M, Glezerman M, et al. Tumor microRNA expression patterns associated with resistance to platinum based chemotherapy and survival in ovarian cancer patients. Gynecologic oncology. 2009; 114: 253-9.

83. Cruz IN, Coley HM, Kramer HB, Madhuri TK, Safuwan NA, Angelino AR, et al. Proteomics Analysis of Ovarian Cancer Cell Lines and Tissues Reveals Drug Resistance-associated Proteins. Cancer Genomics Proteomics. 2017; 14: $35-51$.

84. Lancet JE, Willman CL, Bennett JM. Acute myelogenous leukemia and aging. Clinical interactions. Hematol Oncol Clin North Am. 2000; 14: 251-67.

85. Lichtman SM, Hollis D, Miller AA, Rosner GL, Rhoades CA, Lester EP, et al. Prospective evaluation of the relationship of patient age and paclitaxel clinical pharmacology: Cancer and Leukemia Group B (CALGB 9762). J Clin Oncol. 2006; 24: 1846-51.

86. Lichtman SM, Wildiers H, Chatelut E, Steer C, Budman D, Morrison VA, et al. International Society of Geriatric Oncology Chemotherapy Taskforce: evaluation of chemotherapy in older patients--an analysis of the medical literature. J Clin Oncol. 2007; 25: 1832-43. 
87. George A, Kaye S, Banerjee S. Delivering widespread BRCA testing and PARP inhibition to patients with ovarian cancer. Nature reviews Clinical oncology. 2017; 14: 284-96.

88. Lord CI, Ashworth A. BRCAness revisited. Nat Rev Cancer. 2016; 16: 110-20.

89. Tutt A, Robson M, Garber JE, Domchek SM, Audeh MW, Weitzel JN, et al. Oral poly(ADP-ribose) polymerase inhibitor olaparib in patients with BRCA1 or BRCA2 mutations and advanced breast cancer: a proof-of-concept trial. Lancet. 2010; 376: 235-44

90. Chen BP, Li M, Asaithamby A. New insights into the roles of ATM and DNA-PKcs in the cellular response to oxidative stress. Cancer Lett. 2012; 327: 103-10.

91. Bartek J, Lukas J. Chk1 and Chk2 kinases in checkpoint control and cancer. Cancer Cell. 2003; 3: 421-9.

92. Abdel-Fatah TM, Arora A, Moseley P, Coveney C, Perry C, Johnson K, et al. ATM, ATR and DNA-PKcs expressions correlate to adverse clinical outcomes in epithelial ovarian cancers. BBA Clin. 2014; 2: 10-7.

93. Guffanti F, Fruscio R, Rulli E, Damia G. The impact of DNA damage response gene polymorphisms on therapeutic outcomes in late stage ovarian cancer. Sci Rep. 2016; 6: 38142.

94. Winham SJ, Pirie A, Chen YA, Larson MC, Fogarty ZC, Earp MA, et al. Investigation of Exomic Variants Associated with Overall Survival in Ovarian Cancer. Cancer Epidemiol Biomarkers Prev. 2016; 25: 446-54.

95. Herbig U, Ferreira M, Condel L, Carey D, Sedivy JM. Cellular senescence in aging primates. Science. 2006; 311: 1257

96. DePinho RA. The age of cancer. Nature. 2000; 408: 248-54.

97. Krtolica A, Parrinello S, Lockett S, Desprez PY, Campisi J. Senescent fibroblasts promote epithelial cell growth and tumorigenesis: a link between cancer and aging. Proc Natl Acad Sci U S A. 2001; 98: 12072-7.

98. Brustmann H. Immunohistochemical detection of human telomerase reverse transcriptase (hTERT) and c-kit in serous ovarian carcinoma: a clinicopathologic study. Gynecol Oncol. 2005; 98: 396-402.

99. Lee YK, Chung HH, Kim JW, Song YS, Park NH. Expression of phosphorylated Akt and hTERT is associated with prognosis of epithelial ovarian carcinoma. International journal of clinical and experimental pathology. 2015; 8: 14971-6

100. Kotsopoulos J, Prescott J, De Vivo I, Fan I, McLaughlin J, Rosen B, et al. Telomere length and mortality following a diagnosis of ovarian cancer. Cancer Epidemiol Biomarkers Prev. 2014; 23: 2603-6.

101. Al-Khalaf HH, Nallar SC, Kalvakolanu DV, Aboussekhra A. p16INK4A enhances the transcriptional and the apoptotic functions of p53 through DNA-dependent interaction. Mol Carcinog. 2017.

102. Plisiecka-Halasa J, Karpinska G, Szymanska T, Ziolkowska I, Madry R, Timorek A, et al. P21WAF1, P27KIP1, TP53 and C-MYC analysis in 204 ovarian carcinomas treated with platinum-based regimens. Ann Oncol. 2003; 14: 1078-85.

103. Shandiz FH, Kadkhodayan S, Ghaffarzadegan K, Esmaeily H, Torabi S, Khales SA. The impact of p16 and HER2 expression on survival in patients with ovarian carcinoma. Neoplasma. 2016; 63: 816-21.

104. Brachova P, Thiel KW, Leslie KK. The consequence of oncomorphic TP53 mutations in ovarian cancer. Int J Mol Sci. 2013; 14: 19257-75.

105. Hall J, Paul J, Brown R. Critical evaluation of p53 as a prognostic marker in ovarian cancer. Expert Rev Mol Med. 2004; 6: 1-20.

106. de Magalhaes JP. How ageing processes influence cancer. Nat Rev Cancer. 2013; 13: 357-65.

107. Chen W, Kimura M, Kim S, Cao X, Srinivasan SR, Berenson GS, et al. Longitudinal versus cross-sectional evaluations of leukocyte telomere length dynamics: age-dependent telomere shortening is the rule. J Gerontol A Biol Sci Med Sci. 2011; 66: 312-9.

108. Donehower LA. Using mice to examine p53 functions in cancer, aging, and longevity. Cold Spring Harb Perspect Biol. 2009; 1: a001081.

109. Sanoff HK, Deal AM, Krishnamurthy J, Torrice C, Dillon P, Sorrentino J, et al. Effect of cytotoxic chemotherapy on markers of molecular age in patients with breast cancer. J Natl Cancer Inst. 2014; 106: dju057.

110. Falandry C, Horard B, Bruyas A, Legouffe E, Cretin J, Meunier J, et al. Telomere length is a prognostic biomarker in elderly advanced ovarian cancer patients: a multicenter GINECO study. Aging (Albany NY). 2015.

111. Zittermann A, Iodice S, Pilz S, Grant WB, Bagnardi V, Gandini S. Vitamin D deficiency and mortality risk in the general population: a meta-analysis of prospective cohort studies. Am J Clin Nutr. 2012; 95: 91-100.

112. Li M, Chen P, Li J, Chu R, Xie D, Wang H. Review: the impacts of circulating 25-hydroxyvitamin D levels on cancer patient outcomes: a systematic review and meta-analysis. J Clin Endocrinol Metab. 2014; 99: 2327-36.

113. Pittas AG, Laskowski U, Kos L, Saltzman E. Role of vitamin D in adults requiring nutrition support. JPEN J Parenter Enteral Nutr. 2010; 34: 70-8

114. Wong G, Lim WH, Lewis J, Craig JC, Turner R, Zhu K, et al. Vitamin D and cancer mortality in elderly women. BMC Cancer. 2015; 15: 106.

115. Webb PM, de Fazio A, Protani MM, Ibiebele TI, Nagle CM, Brand AH, et al. Circulating 25-hydroxyvitamin D and survival in women with ovarian cancer. Am J Clin Nutr. 2015; 102: 109-14.

116. Granato T, Manganaro L, Petri L, Porpora MG, Viggiani V, Angeloni A, et al. Low 25-OH vitamin D levels at time of diagnosis and recurrence of ovarian cancer. Tumour Biol. 2016; 37: 2177-81.

117. Hagenau T, Vest R, Gissel TN, Poulsen CS, Erlandsen M, Mosekilde L, et al. Global vitamin D levels in relation to age, gender, skin pigmentation and latitude: an ecologic meta-regression analysis. Osteoporos Int. 2009; 20: 133-40.
118. Holick MF, Matsuoka LY, Wortsman J. Age, vitamin D, and solar ultraviolet. Lancet. 1989; 2: 1104-5.

119. Richards JB, Valdes AM, Gardner JP, Paximadas D, Kimura M, Nessa A, et al. Higher serum vitamin D concentrations are associated with longer leukocyte telomere length in women. Am J Clin Nutr. 2007; 86: 1420-5.

120. De Vita F, Lauretani F, Bauer J, Bautmans I, Shardell M, Cherubini A, et al. Relationship between vitamin D and inflammatory markers in older individuals. Age (Dordr). 2014; 36: 9694.

121. Brahmkhatri VP, Prasanna C, Atreya HS. Insulin-like growth factor system in cancer: novel targeted therapies. Biomed Res Int. 2015; 2015: 538019.

122. Rosenzweig SA, Atreya HS. Defining the pathway to insulin-like growth factor system targeting in cancer. Biochem Pharmacol. 2010; 80: 1115-24.

123. Mita K, Nakahara M, Usui T. Expression of the insulin-like growth factor system and cancer progression in hormone-treated prostate cancer patients. Int J Urol. 2000; 7: 321-9.

124. Rowlands MA, Holly JM, Hamdy F, Phillips J, Goodwin L, Marsden G, et al. Serum insulin-like growth factors and mortality in localised and advanced clinically detected prostate cancer. Cancer Causes Control. 2012; 23: 347-54.

125. Brokaw J, Katsaros D, Wiley A, Lu L, Su D, Sochirca O, et al. IGF-I in epithelial ovarian cancer and its role in disease progression. Growth Factors. 2007; 25: $346-54$.

126. Yunusova NV, Villert AB, Spirina LV, Frolova AE, Kolomiets LA, Kondakova IV. Insulin-Like Growth Factors and Their Binding Proteins in Tumors and Ascites of Ovarian Cancer Patients: Association With Response To Neoadjuvant Chemotherapy. Asian Pac J Cancer Prev. 2016; 17: 6215-20.

127. Sayer RA, Lancaster JM, Pittman J, Gray J, Whitaker R, Marks JR, et al. High insulin-like growth factor-2 (IGF-2) gene expression is an independent predictor of poor survival for patients with advanced stage serous epithelial ovarian cancer. Gynecologic oncology. 2005; 96: 355-61.

128. Lu L, Katsaros D, Wiley A, Rigault de la Longrais IA, Risch HA, Puopolo M, et al. The relationship of insulin-like growth factor-II, insulin-like growth factor binding protein-3, and estrogen receptor-alpha expression to disease progression in epithelial ovarian cancer. Clin Cancer Res. 2006; 12: 1208-14.

129. Dong Y, Li J, Han F, Chen H, Zhao X, Oin O, et al. High IGF2 expression is associated with poor clinical outcome in human ovarian cancer. Oncol Rep. 2015; 34: 936-42.

130. Janssen JA, Stolk RP, Pols HA, Grobbee DE, de Jong FH, Lamberts SW. Serum free IGF-I, total IGF-I, IGFBP-1 and IGFBP-3 levels in an elderly population: relation to age and sex steroid levels. Clin Endocrinol (Oxf). 1998; 48: 471-8.

131. Raynaud-Simon A. Levels of plasma insulin-like growth factor I (IGF I), IGF II, IGF binding proteins, type 1 IGF receptor and growth hormone binding protein in community-dwelling elderly subjects with no malnutrition and no inflammation. J Nutr Health Aging. 2003; 7: 267-73.

132. Chen $P$, Huhtinen $K$, Kaipio K, Mikkonen P, Aittomaki V, Lindell R, et al. Identification of Prognostic Groups in High-Grade Serous Ovarian Cancer Treated with Platinum-Taxane Chemotherapy. Cancer Res. 2015; 75: 2987-98.

133. Teschendorff AE, Lee SH, Jones A, Fiegl H, Kalwa M, Wagner W, et al. HOTAIR and its surrogate DNA methylation signature indicate carboplatin resistance in ovarian cancer. Genome Med. 2015; 7: 108

134. Horvath S, Raj K. DNA methylation-based biomarkers and the epigenetic clock theory of ageing. Nat Rev Genet. 2018; 19: 371-84.

135. Levine ME, Hosgood HD, Chen B, Absher D, Assimes T, Horvath S. DNA methylation age of blood predicts future onset of lung cancer in the women's health initiative. Aging. 2015; 7: 690-700.

136. Teschendorff AE, Menon U, Gentry-Maharaj A, Ramus SJ, Gayther SA, Apostolidou S, et al. An epigenetic signature in peripheral blood predicts active ovarian cancer. PLoS One. 2009; 4: e8274.

137. Lim LP, Lau NC, Garrett-Engele P, Grimson A, Schelter JM, Castle J, et al. Microarray analysis shows that some microRNAs downregulate large numbers of target mRNAs. Nature. 2005; 433: 769-73.

138. [Internet] miRDB: http://mirdb.org/statistics.html; 2014

139. Cancer Genome Atlas Research N. Integrated genomic analyses of ovarian carcinoma. Nature. 2011; 474: 609-15.

140. Katz B, Trope CG, Reich R, Davidson B. MicroRNAs in Ovarian Cancer. Hum Pathol. 2015; 46: 1245-56.

141. Prahm KP, Novotny GW, Hogdall C, Hogdall E. Current status on microRNAs as biomarkers for ovarian cancer. Apmis. 2016; 124: 337-55.

142. Dluzen DF, Noren Hooten N, Evans MK. Extracellular RNA in aging. Wiley Interdiscip Rev RNA. 2017; 8

143. Gaur A, Jewell DA, Liang Y, Ridzon D, Moore JH, Chen C, et al. Characterization of microRNA expression levels and their biological correlates in human cancer cell lines. Cancer Res. 2007; 67: 2456-68.

144. Lu J, Getz G, Miska EA, Alvarez-Saavedra E, Lamb J, Peck D, et al. MicroRNA expression profiles classify human cancers. Nature. 2005; 435: 834-8.

145. Deb B, Uddin A, Chakraborty S. miRNAs and ovarian cancer: An overview. J Cell Physiol. 2018; 233: 3846-54.

146. Schneider A, Matkovich SJ, Victoria B, Spinel L, Bartke A, Golusinski P, et al. Changes of Ovarian microRNA Profile in Long-Living Ames Dwarf Mice during Aging. PLoS One. 2017; 12: e0169213.

147. Weidle UH, Birzele F, Kollmorgen G, Nopora A. Potential microRNA-related Targets for Therapeutic Intervention with Ovarian Cancer Metastasis. Cancer Genomics Proteomics. 2018; 15: 1-15.

148. Olivieri F, Spazzafumo L, Santini G, Lazzarini R, Albertini MC, Rippo MR, et al. Age-related differences in the expression of circulating microRNAs: miR-21 
as a new circulating marker of inflammaging. Mech Ageing Dev. 2012; 133: 675-85.

149. Liang DY, Hou YQ, Luo LJ, Ao L. Altered expression of miR-92a correlates with Th17 cell frequency in patients with primary biliary cirrhosis. Int J Mol Med. 2016; 38: 131-8

150. Qin A, Wen Z, Zhou Y, Li Y, Li Y, Luo J, et al. MicroRNA-126 regulates the induction and function of $\mathrm{CD} 4(+)$ Foxp3(+) regulatory $\mathrm{T}$ cells through PI3K/AKT pathway. J Cell Mol Med. 2013; 17: 252-64.

151. Mattes J, Collison A, Plank M, Phipps S, Foster PS. Antagonism of microRNA-126 suppresses the effector function of TH2 cells and the development of allergic airways disease. Proc Natl Acad Sci U S A. 2009; 106: 18704-9.

152. Tang ST, Wang F, Shao M, Wang Y, Zhu HQ. MicroRNA-126 suppresses inflammation in endothelial cells under hyperglycemic condition by targeting HMGB1. Vascul Pharmacol. 2017; 88: 48-55.

153. Wang Y, Liang J, Qin H, Ge Y, Du J, Lin J, et al. Elevated expression of miR-142-3p is related to the pro-inflammatory function of monocyte-derived dendritic cells in SLE. Arthritis Res Ther. 2016; 18: 263.

154. Naqvi AR, Fordham JB, Ganesh B, Nares S. miR-24, miR-30b and miR-142-3p interfere with antigen processing and presentation by primary macrophages and dendritic cells. Sci Rep. 2016; 6: 32925.

155. Cheng X, Zhang X, Su J, Zhang Y, Zhou W, Zhou J, et al. miR-19b downregulates intestinal SOCS3 to reduce intestinal inflammation in Crohn's disease. Sci Rep. 2015; 5: 10397.

156. Gantier MP, Stunden HJ, McCoy CE, Behlke MA, Wang D, Kaparakis-Liaskos $\mathrm{M}$, et al. A miR-19 regulon that controls NF-kappaB signaling. Nucleic Acids Res. 2012; 40: 8048-58.

157. Philippe L, Alsaleh G, Suffert G, Meyer A, Georgel P, Sibilia J, et al. TLR2 expression is regulated by microRNA miR-19 in rheumatoid fibroblast-like synoviocytes. J Immunol. 2012; 188: 454-61.

158. Gidlof $O$, Sathanoori $R$, Magistri M, Faghihi MA, Wahlestedt $C$, Olde B, et al. Extracellular Uridine Triphosphate and Adenosine Triphosphate Attenuate Endothelial Inflammation through miR-22-Mediated ICAM-1 Inhibition. J Vasc Res. 2015; 52: 71-80

159. Gu W, Zhan H, Zhou XY, Yao L, Yan M, Chen A, et al. MicroRNA-22 regulates inflammation and angiogenesis via targeting VE-cadherin. FEBS Lett. 2017; 591: 513-26.

160. Pua HH, Steiner DF, Patel S, Gonzalez JR, Ortiz-Carpena JF, Kageyama R, et al. MicroRNAs 24 and 27 Suppress Allergic Inflammation and Target a Network of Regulators of T Helper 2 Cell-Associated Cytokine Production. Immunity. 2016; 44: 821-32.

161. Tang H, Jiang H, Zheng J, Li J, Wei Y, Xu G, et al. MicroRNA-106b regulates pro-allergic properties of dendritic cells and Th2 polarisation by targeting early growth response-2 in vitro. Int Immunopharmacol. 2015; 28: 866-74.

162. Cioffi M, Trabulo SM, Vallespinos M, Raj D, Kheir TB, Lin ML, et al. The miR-25-93-106b cluster regulates tumor metastasis and immune evasion via modulation of CXCL12 and PD-L1. Oncotarget. 2017; 8: 21609-25.

163. Smith NL, Wissink EM, Grimson A, Rudd BD. miR-150 Regulates Differentiation and Cytolytic Effector Function in CD8+ T cells. Sci Rep. 2015; 5: 16399.

164. Sang W, Wang Y, Zhang C, Zhang D, Sun C, Niu M, et al. MiR-150 impairs inflammatory cytokine production by targeting ARRB-2 after blocking CD28/B7 costimulatory pathway. Immunol Lett. 2016; 172: 1-10.

165. Banerjee A, Schambach F, DeJong CS, Hammond SM, Reiner SL. Micro-RNA-155 inhibits IFN-gamma signaling in CD4+ T cells. Eur J Immunol. 2010; 40: 225-31.

166. Curtale G, Citarella F, Carissimi C, Goldoni M, Carucci N, Fulci V, et al. An emerging player in the adaptive immune response: microRNA-146a is a modulator of IL-2 expression and activation-induced cell death in T lymphocytes. Blood. 2010; 115: 265-73.

167. Lu LF, Boldin MP, Chaudhry A, Lin LL, Taganov KD, Hanada T, et al. Function of miR-146a in controlling Treg cell-mediated regulation of Th1 responses. Cell. 2010; 142: 914-29.

168. Rodriguez A, Vigorito E, Clare S, Warren MV, Couttet P, Soond DR, et al. Requirement of bic/microRNA-155 for normal immune function. Science. 2007; 316: 608-11.

169. Doxaki C, Kampranis SC, Eliopoulos AG, Spilianakis C, Tsatsanis C. Coordinated Regulation of miR-155 and miR-146a Genes during Induction of Endotoxin Tolerance in Macrophages. J Immunol. 2015; 195: 5750-61.

170. Boldin MP, Taganov KD, Rao DS, Yang L, Zhao JL, Kalwani M, et al. miR-146a is a significant brake on autoimmunity, myeloproliferation, and cancer in mice. J Exp Med. 2011; 208: 1189-201.

171. O'Connell RM, Rao DS, Chaudhuri AA, Baltimore D. Physiological and pathological roles for microRNAs in the immune system. Nat Rev Immunol. 2010; 10: 111-22

172. Carmeliet $P$, Dor $Y$, Herbert JM, Fukumura D, Brusselmans K, Dewerchin $M$, et al. Role of HIF-1alpha in hypoxia-mediated apoptosis, cell proliferation and tumour angiogenesis. Nature. 1998; 394: 485-90.

173. Semenza GL. HIF-1: upstream and downstream of cancer metabolism. Curr Opin Genet Dev. 2010; 20: 51-6.

174. Kong D, Shi S, Li Y. Single nucleotide polymorphisms in the D-loop region of mitochondrial DNA are associated with epithelial ovarian cancer prognosis. Mitochondrial DNA. 2015; 26: 848-50.
175. Kurita T, Izumi H, Kagami S, Kawagoe T, Toki N, Matsuura $\mathrm{Y}$, et al. Mitochondrial transcription factor A regulates BCL2L1 gene expression and is a prognostic factor in serous ovarian cancer. Cancer Sci. 2012; 103: 239-444.

176. Jin Y, Wang H, Liang X, Ma J, Wang Y. Pathological and prognostic significance of hypoxia-inducible factor 1alpha expression in epithelial ovarian cancer: a meta-analysis. Tumour Biol. 2014; 35: 8149-59.

177. Cannizzo ES, Clement CC, Sahu R, Follo C, Santambrogio L. Oxidative stress, inflamm-aging and immunosenescence. J Proteomics. 2011; 74: 2313-23.

178. Zhang Y, Ertl HC. Aging: T cell metabolism within tumors. Aging (Albany NY). 2016; 8: 1163-4.

179. Zorov DB, Popkov VA, Zorova LD, Vorobjev IA, Pevzner IB, Silachev DN, et al. Mitochondrial Aging: Is There a Mitochondrial Clock? J Gerontol A Biol Sci Med Sci. 2016.

180. Soro-Arnaiz I, Li OOY, Torres-Capelli M, Melendez-Rodriguez F, Veiga S, Veys K, et al. Role of Mitochondrial Complex IV in Age-Dependent Obesity. Cell Rep. 2016; 16: 2991-3002.

181. Bandera EV, Lee VS, Qin B, Rodriguez-Rodriguez L, Powell CB, Kushi LH. Impact of body mass index on ovarian cancer survival varies by stage. $\mathrm{Br} \mathrm{J}$ Cancer. 2017; 117: 282-9.

182. Purcell SA, Elliott SA, Kroenke CH, Sawyer MB, Prado CM. Impact of Body Weight and Body Composition on Ovarian Cancer Prognosis. Curr Oncol Rep. 2016; $18: 8$. 